\title{
Dietary oxidative stress and antioxidant defense with an emphasis on plant extract administration
}

\author{
Aristidis S. Veskoukis • Aristidis M. Tsatsakis • \\ Dimitrios Kouretas
}

Received: 21 July 2011 /Revised: 11 September 2011 /Accepted: 13 September 2011 /Published online: 30 September 2011

(C) The Author(s) 2011. This article is published with open access at Springerlink.com

\begin{abstract}
Eukaryotic cells generally function in a reduced state, but an amount of reactive species is essential for several biochemical processes. The antioxidant network is the defensive mechanism that occurs when the concentration of reactive species exceeds a threshold. Polyphenolic compounds present in plant extracts are potent antioxidants in vitro, but they may promote oxidative stress when administered in animals and humans, especially when given as supplements in exercise, a modality usually adopted as an oxidant stimulus. This is mainly observed when antioxidant molecules are administered separately and not as part of a diet. Exercise is usually adopted as a physiological model for examining the effects of reactive species in human or animal physiology. The use of exercise as a model demonstrates that reactive species do not always have adverse effects, but are necessary in physiological processes that are beneficial for human health. This review summarizes what is known about antioxidant supplementation and demonstrates the need for a meticulous examination of the in vitro findings before applying them to in vivo models. The term "antioxidant" seems elusive, and it is more appropriate to characterize a compound as "antioxidant" if we know in which
\end{abstract}

\section{A. S. Veskoukis $\cdot$ D. Kouretas}

Department of Biochemistry and Biotechnology,

University of Thessaly,

Larissa 41221, Greece

\author{
A. M. Tsatsakis $(\square)$ \\ Forensic Sciences and Toxicology Department, Medical School, \\ University of Crete, \\ 71003 Heraklion, Crete P.O. Box 1393, Greece \\ e-mail: aris@med.uoc.gr
}

concentration it is used, when it is used, and under which conditions.

Keywords Antioxidants · Plant extracts · Exercise $\cdot$ In vitro $\cdot$ In vivo $\cdot$ Reactive species

\section{Biochemistry of reactive species: an overview}

Reactive species are unstable, highly reactive structures. They may be free radicals which possess an unpaired electron in their outer orbit and are capable of independent existence. Their half-lives vary from a few nanoseconds for the most reactive compounds to seconds and hours for rather stable radicals. They trigger chain reactions resulting in the oxidation of macromolecules in order to reach a steady state. They are divided into four main categories based on their central atom, specifically reactive oxygen species (ROS), reactive nitrogen species (RNS), reactive sulfur species, and reactive chloride species, derived from oxygen, nitrogen, sulfur, and chloride, respectively (Halliwell and Gutteridge 2007). ROS is the main category of reactive species produced from molecular oxygen $\left(\mathrm{O}_{2}\right)$ with partial chemical reductions. One of the most abundant reactive species is superoxide anion $\left(\mathrm{O}_{2}{ }^{-{ }^{-}}\right)$, which is generated by $\mathrm{O}_{2}$ following reduction by one electron. When $\mathrm{O}_{2}$ is reduced by two and three electrons, hydrogen peroxide $\left(\mathrm{H}_{2} \mathrm{O}_{2}\right)$ and hydroxyl radical $\left(\mathrm{OH}^{-}\right)$are produced, respectively. Finally, $\mathrm{H}_{2} \mathrm{O}$ is produced after the full reduction of $\mathrm{O}_{2}$ by four electrons (Simic 1988). The most harmful reactive species is $\mathrm{OH}$, which is generated by Fenton and Haber-Weiss reactions in the presence of a transition metal, usually iron $(\mathrm{Fe})$ or copper $(\mathrm{Cu})$. Hydrogen peroxide has a relatively long half-life and can 
be transfered through membrane transport far from the place of its generation. Hydrogen peroxide is not a free radical, but it may have detrimental effects on DNA, proteins, and lipids when its concentration reaches $10 \mu \mathrm{M}$ (Halliwell and Gutteridge 2007). Nitric oxide radical (NO) is the most common RNS. It is derived by the amino acid L-arginine and is highly reactive. It reacts with $\mathrm{O}_{2}{ }^{--}$, generating peroxynitrite anion $\left(\mathrm{ONOO}^{-}\right)$, which is converted to peroxynitrous acid and finally to harmful $\mathrm{OH}^{-}$ and nitrite anion $\left(\mathrm{NO}_{2} ;\right.$; Halliwell 2001a).

Reactive oxygen and nitrogen species are physiologically produced during metabolic processes and especially during electron transport chain reactions (Di Meo and Venditti 2001). An initial study has reported that $2-5 \%$ of $\mathrm{O}_{2}$ used during oxidative phosphorylation in skeletal muscle mitochondria is reduced to $\mathrm{O}_{2}{ }^{--}$at rest (Sjodin et al. 1990). More recent studies have demonstrated that, at rest, reactive species leakage in heart mitochondria ranges from $0.4 \%$ to $0.8 \%$ (Hansford et al. 1997) or at an even lower percentage $(0.15 \%)$ in skeletal muscle (St-Pierre et al. 2002). Another internal source of reactive species is peroxisomes, small membrane-enclosed organelles containing enzymes important for oxidation reactions. Furthermore, the enzymes of the $\mathrm{P}_{450}$ complex generate reactive species during the detoxification of xenobiotics, such as drugs. There are also external sources of reactive species related to UV radiation, air pollution, smoking, alcohol consumption, and exercise (Halliwell and Gutteridge 2007).

Reactive species are often considered to be harmful entities because of their connection to oxidative damage in biomolecules. Nevertheless, this is not always the case. The biology of reactive species follows the phenomenon of hormesis. Accordingly, when reactive species are present in low concentrations, they are necessary for fundamental procedures in the subcellular environment. If their concentrations exceed a limit, however, they may have detrimental effects on DNA, proteins, and lipids. It appears that human cells generally function in a reduced state, but an amount of reactive species is essential for several biochemical processes. Signal transduction requires the presence of $\mathrm{O}_{2}{ }^{-}$ and $\mathrm{H}_{2} \mathrm{O}_{2}$ (Ji 2007), whereas $\mathrm{NO}^{\circ}$ is a neurotransmitter and is biologically important for vasoconstriction (Halliwell and Gutteridge 2007). Reactive species are also vital for muscle contraction (Linnane et al. 2002), enzyme activation (Jenkins 1988), and gene expression (Ji et al. 2006), while several gene transcription factors require transient oxidation for their function (Sen 1998). Furthermore, reactive species contribute to the normal function of the immune system via the activation of phagocytes, a common procedure in conditions in which inflammation occurs, such as muscledamaging (eccentric) exercise (Malm 2001). Additionally, folding of nascent proteins in the endoplasmic reticulum is aided by a more oxidized environment to permit disulfide bridge formation (Suh et al. 1999). Apoptosis is also accompanied by a degree of intracellular increased oxidation, although too much oxidation stops apoptosis by oxidizing and inactivating caspases (Hampton and Orrenius 1998).

As previously mentioned, the concentration of reactive species is a key factor in their effect. If the concentration is excessively high, they may become very harmful for macromolecules. Proteins are one of the major targets of reactive species which induce the formation of carbonyl groups (aldehydes and ketones) in those amino acids that are susceptible to oxidation, such as histidine, arginine, lysine, and proline. The carbonyl groups are not metabolized in proteasomes and lysosomes, but are accumulated (Levine 2002). Furthermore, the thiol groups (-SH) present in protein molecules are oxidized in thiol radicals (RS). Protein oxidation leads to conformational changes which result in the modification or loss of protein function (Halliwell and Gutteridge 2007). Apart from proteins, lipids are vulnerable in reactive species-induced oxidative damage (Halliwell and Chirico 1993). Polyunsaturated fatty acids (PUFA) are abundant in cellular membranes and are susceptible to oxidation, leading to lipid peroxidation chain reactions (Alessio 1993). Specifically, PUFA oxidation induces the generation of a radical, which reacts with $\mathrm{O}_{2}$ and produces peroxyl radicals (LOO'). These radicals further oxidize PUFA and lipid peroxides (LOOH) are produced, which create conjugated dienes as by-products, such as 4-hydroxy-2-nonenal and malonyl dialdehyde (Young and McEneny 2001; Mylonas and Kouretas 1999). Lipid peroxidation increases the permeability of cellular membranes, resulting in cell death. Reactive species also affect DNA by causing chain breaks and damaging its repair mechanism (Jenkins 1988). DNA, and especially guanine, oxidation results in the production of 8hydroxy-2'-deoxyguanosine. This by-product, if not repaired, induces DNA mutations that may cause aging and carcinogenesis (Radak et al. 1999). In addition, excessive production of reactive species has been implicated in immune system dysfunction (Schneider and Tiidus 2007), muscle damage (Nikolaidis et al. 2007a, b), and fatigue (Betters et al. 2004).

\section{Endogenous and dietary antioxidants}

As explained previously, oxygen, the base element for the favorable aspects of aerobic life, is poisonous in some ways and is linked to the potentially dangerous oxidative damage of macromolecules. Aerobic organisms must therefore adopt ways to survive these harmful effects. This defensive mechanism is the antioxidant system (Halliwell and Gutteridge 2007). There is no simple definition of an 
antioxidant. Halliwell and Gutteridge (1995) attempted to define an antioxidant as "any substance that when present at low concentrations compared with those of an oxidizable substrate (every organic molecule found in vivo) significantly delays or prevents oxidation of that substrate." However, this definition seems inadequate in certain cases. Plasma albumin is considered an important antioxidant molecule because it binds copper and protects extracellular targets such as low-density lipoproteins (LDLs) against oxidative damage. However, albumin is in considerable molar excess compared with LDLs (Halliwell 1995). Therefore, an antioxidant might be defined more simply as "any substance that delays, prevents or removes oxidative damage to a target molecule" (Halliwell and Gutteridge 2007).

Antioxidants can be divided into categories according to specific characteristics. They include enzymes such as superoxide dismutase (SOD), catalase, glutathione reductase, and glutathione peroxidase (GPX) and non-enzymatic metabolites such as glutathione, uric acid, vitamins, and polyphenols. Regarding their origin, various antioxidants such as glutathione, uric acid, catalase and SOD can be synthesized in vivo, whereas others, namely, polyphenols and $\beta$-carotene, are obtained from food. Based on their physical properties, antioxidants can be divided into watersoluble antioxidants such as uric acid, glutathione, and polyphenols or lipid-soluble antioxidants such as vitamins $\mathrm{A}$ and $\mathrm{E}$ and lipoic acid.

The SOD enzyme catalyzes the dismutation of $\mathrm{O}_{2}{ }^{--}$to $\mathrm{H}_{2} \mathrm{O}_{2}$. It exists in mitochondrial form (MnSOD) and in cytoplasmic form $(\mathrm{Cu} / \mathrm{ZnSOD})$ that is primarily found in muscle cells (Das et al. 1997). Catalase is present in almost every kind of cell, but its concentration is higher in the erythrocytes and liver (Masters et al. 1986). Its subcellular localization is in peroxisomes, in mitochondria, and in the nucleus. It catalyzes the conversion of $\mathrm{H}_{2} \mathrm{O}_{2}$, which is produced by SOD to $\mathrm{H}_{2} \mathrm{O}$ and $\mathrm{O}_{2}$. The antioxidant activity of catalase is of great significance as it prevents the conversion of $\mathrm{H}_{2} \mathrm{O}_{2}$ to the very harmful $\mathrm{OH}$. Furthermore, it has been demonstrated that catalase and SOD activities exhibit a linear correlation with life span in mammals (Cutler 1984). GPX, which requires selenium as a cofactor, is present in the cytoplasm and mitochondria and is an alternative route of $\mathrm{H}_{2} \mathrm{O}_{2}$ degradation. Specifically, $\mathrm{H}_{2} \mathrm{O}_{2}$ is converted to $\mathrm{H}_{2} \mathrm{O}$ and $\mathrm{O}_{2}$ and oxidizes GSH (reduced form of glutathione) to GSSG (oxidized form of glutathione).

Glutathione is considered one of the most important antioxidant metabolites and is the first line of defense against reactive species. At rest, glutathione is usually present in the reduced state. GSH is a tripeptide consisting of glutamic acid, cysteine, and glycine. It is the most abundant low-molecular-weight thiol-containing compound in biological fluids and tissues of mammals. In eukaryotic cells, $90 \%$ of the intracellular GSH pool resides in the cytoplasm, and the remaining $10 \%$ is found in the mitochondria, endoplasmic reticulum, and the nucleus. However, the biosynthesis of GSH appears to occur exclusively in the cytoplasm. Intracellular GSH concentration is estimated to range from 0.5 to $10 \mathrm{mM}$ (Barycki 2007). GSH possesses potent antioxidant properties, maintaining the intracellular redox homeostasis due to the thiol group of cysteine which serves as a substrate of GPX (Halliwell and Gutteridge 2007). Glutathione is important for the regeneration of antioxidant vitamins $\mathrm{E}$ and $\mathrm{C}$ (May et al. 1996) and contributes to xenobiotic detoxification (Halliwell and Gutteridge 2007). In physiological conditions, GSH is in a dynamic equilibrium with GSSG. However, in the context of oxidative stress, GSH works with GPX to efficiently remove intracellular $\mathrm{H}_{2} \mathrm{O}_{2}$. This process protects biomolecules from oxidative modifications, and GSH is converted to GSSG. Glutathione reductase reduces GSSG to GSH using NADPH as an electron donor, thus replenishing the GSH pool. The ratio of GSH/GSSG is often used as a biomarker of oxidative stress. It has been suggested that the GSH/GSSG ratio in the endoplasmic reticulum, in which the more oxidized environment aids protein folding, is as low as $1: 1$, in contrast to the mitochondria and the cytosol where the GSH/GSSG ratio is $>10$ (Barycki 2007). This is not always precise, however. As mentioned earlier, glutathione participates in several different biochemical processes, namely, in the regulation of protein and DNA synthesis and as an essential cofactor of many enzymes (Halliwell and Gutteridge 2007; Afzal et al. 2002). This fact can affect the ratio of GSH/GSSG and cause its conversion from the reduced to the oxidized form. Therefore, the use of the GSH/GSSG ratio as a biomarker to monitor oxidative stress lacks accuracy and probably needs to be reconsidered.

Polyphenolic compounds constitute a crucial category of antioxidant metabolites. They are plant secondary metabolites which have at least one aromatic ring in their molecule and usually exist in the form of glycosides. They protect plants against harmful environmental conditions and the attack of microorganisms and contribute to the development of several characteristics such as color (Manach et al. 2004). More than 8,000 different polyphenolic compounds have been described. They are subdivided into nonflavonoids (e.g., hydrobenzoic acids, hydroxycinnamic acids, and stilbenes) and flavonoids (e.g., flavonols, flavanals, isoflavones, and anthocyanins). Flavonoids are composed of more than 4,000 different species that have two aromatic benzene rings linked through three carbons forming an oxygenated heterocycle. Plant polyphenols possess antioxidant properties as they inactivate free radicals by offering a hydrogen atom and an electron. They are converted into relatively harmless free radicals, which 
may react with other free radicals and inactivate them. Furthermore, they act as metal chelators, mainly $\mathrm{Fe}$ and $\mathrm{Cu}$, thus not allowing them to initiate Fenton and Haber-Weiss reactions (Nijveldt et al. 2001). In addition, they inhibit the activity of enzymes related to reactive species production, such as xanthine oxidase, cyclooxygenase, and lipoxygenase (Rice-Evans et al. 1996; Cotelle 2001). There are numerous studies examining the beneficial effects of polyphenolic compounds on health. It has been demonstrated that consumption of polyphenols results in the prevention of cardiovascular diseases (Hertog et al. 1997) and cancer (Cotelle 2001). Hooper et al. (2010) have also denoted that plants which are stressed by environmental conditions can produce bioactive compounds (including polyphenolic compounds) which offer beneficial health effects, such as stress resistance, and survival benefits to the animals that consume them. This biological principle referred to as "xenohormesis" is of high importance and explains how the environmentally stressed plant compounds can activate the animal's cellular stress response, which in turn results in improving animal fitness and longevity.

\section{Oxidative stress, dietary oxidative stress, and reductive stress}

Oxidative agents and antioxidant mechanisms are in a potential balance. The disturbance of the equilibrium between oxidative mechanisms and antioxidants in favor of the former has been referred to as oxidative stress (Sies 1991). Sixteen years after the first definition of oxidative stress, Sies and Jones (2007) redefined it in a more precise way: "an imbalance between oxidants and antioxidants in favor of the oxidants leading to a disruption of redox signaling and control and/or molecular damage." Following this line of reasoning, oxidative stress is inextricably linked with the disruption of normal signaling pathways, damage of macromolecules, and the disruption of homeostasis. The aforementioned definitions imply that oxidative stress is a result of pathophysiological circumstances or is even a cause of such processes. However, it should be noted that oxygen is not evenly distributed in tissues and cells, and therefore there are sites that are under physiological oxidative stress (Sies and Jones 2007). What is the threshold between pathological and physiological oxidative stress? This is a difficult question to answer. There are many studies in the redox biology field describing experiments in which two or more different treatments are compared. A treatment is usually considered to induce oxidative stress when the concentration of the products derived from the oxidation of macromolecules is elevated compared with another treatment or with baseline values. Nevertheless, it is difficult to adopt a threshold value of the concentrations of such products in order to monitor oxidative stress. The concentration of oxidation products and antioxidant molecules could serve as a useful parameter in this regard, however (Sies and Jones 2007). In 1995, Levander et al. (1995) introduced a new term, the "dietary oxidative stress." It denotes the disturbance of cell redox status caused exclusively by diet via the excess uptake of oxidative load or the impaired availability of antioxidants. The use of the term "dietary oxidative stress" confirms the excessive role that has been given to nutrition from scientists, but apparently follows the rules of redox biology.

Every reference in the condition called oxidative stress is absolutely linked to a balance between the pool of oxidant and antioxidant mechanisms. There are two sides in this balance which have not been equally studied. On one side, oxidative stress occurs when the disturbance of the balance favors the oxidants, and reductive stress is generated after the enhancement of the antioxidant pool. A search of the Medline database in May 2011 turned up 84,020 papers using the keyword term "oxidative stress," but only 69 using the term "reductive stress." This is proof that the literature has emphasized research on oxidative stress, whereas reductive stress has been rather neglected. However, this huge discrepancy does not reflect the high importance of the reducing side of the equation. Albert Wendel was the first to use the term "reductive stress" in 1987 (Wendel 1987). The term has never been precisely defined, but scientists usually refer to it in relation to the oxidative side of the equation. This is probably because oxidative stress has been extensively studied, whereas reductive stress has been mainly theoretically examined. Common sense tells us that reductive stress is related to conditions in which cells or organelles are in a reductive state. This could be an outcome of respiratory inhibition, a situation that results in decreased reactive species generation. Although it has not been thoroughly examined, reductive stress contributes in signal transduction regulation and gene expression (Kehrer 2007). The indices that have mostly been used for the assessment of reductive stress are the amounts of nicotinamide adenine dinucleotide $\left(\mathrm{NAD}^{+}\right), \mathrm{NADH}$ (the reduced form of nicotinamide adenine dinucleotide), nicotinamide adenine dinucleotide phosphate $\left(\mathrm{NADP}^{+}\right.$), and NADPH (the reduced form of nicotinamide adenine dinucleotide phosphate), as well as the increase in the lactate/pyruvate ratio (Kehrer 2007). Finally, it appears that there is high biological affinity between oxidative stress and reductive stress, and they both play an important role in the redox biology field.

\section{The oxidative potential of plant antioxidants}

The regulation of the cellular redox status is an outcome of several different factors. Thus, the increase in the produc- 
tion of reactive species does not necessarily lead to oxidative stress. Similarly, the increased activity of antioxidant enzymes or the enhanced uptake of antioxidant molecules as dietary components or as nutritional supplements is not synonymous with an improved defense against the harmful effects of reactive species. The oxidative agents and the antioxidant mechanisms are in a potential balance, which is disturbed in favor of the former when oxidative stress occurs (Sies 1991). Moreover, although it sounds contradictory, it is an undoubted fact that antioxidants under specific conditions can have a prooxidant action.

Over the last two decades, there has been increasing scientific evidence of the beneficial health implications of the Mediterranean diet. Polyphenolic compounds and especially flavonoids are present in its main constituents such as grapes, legumes, other kinds of vegetables, fruits, oil, and wine. Polyphenolic compounds are largely known for their antioxidant properties, but they may also act to favor oxidative stress. This is mainly observed when antioxidant molecules are administered individually and not as a part of the diet. Thus, "a protective effect of diet is not equivalent to a protective effect of antioxidants in diet" (Halliwell 2000). There are studies demonstrating such discrepancies. A diet rich in vegetables and fruits appears to decrease the risk of cancer and to increase the concentration of $\beta$-carotene in the blood. On the other hand, administration of $\beta$-carotene does not decrease the likelihood of cancer, but has rather the opposite effect in smokers (Rowe 1996). Fruits and vegetables decrease the free radicalinduced DNA damage in humans, a risk factor for cancer development. In contrast, ascorbate, vitamin $\mathrm{E}$, or $\beta$ carotene administration did not have the same effects in studies reviewed by Halliwell (2000). The phenolic radical, which is formed after scavenging reactive species, may oxidize GSH, generating a thiyl radical (RS) which, reacting with GSH, produces the disulfide radical (GSSG). The latter reduces $\mathrm{O}_{2}$, thus producing $\mathrm{O}_{2}{ }^{--}$(Cotelle 2001). Furthermore, the phenolic radical reduces ferric anion $\left(\mathrm{Fe}^{+++}\right)$to ferrous anion $\left(\mathrm{Fe}^{++}\right)$, which can generate the highly reactive $\mathrm{OH}^{\circ}$ by Fenton reaction (Halliwell and Gutteridge 2007).

This fact might seem surprising, but it has a reasonable explanation. Reactive species are oxidizing agents and the antioxidants that scavenge them are reducing agents. An antioxidant can be a better scavenger in vitro provided that it has an increased reducing capacity and is administered at a high concentration. Thus, when a single antioxidant molecule is administered alone, its concentration in the blood is higher than when it is taken as an ingredient of vegetables or fruits. Apart from the concentration of an antioxidant, the time of administration is of high importance. Transition metals are generated from metalloproteins as an outcome of oxidative damage and are catalysts of oxidative damage. Thus, administration of potent antioxidants after oxidative damage might promote further damage, implying potent prooxidant action. A relative study by Kang et al. (1998) observed that the administration of vitamin $\mathrm{C}$ was protective against oxidative damage induced by the herbicide paraquat in animals. Nevertheless, when vitamin $\mathrm{C}$ was given after animals were exposed to paraquat, it impaired the damage by interacting with the released transition metals (Kang et al. 1998). Although this paradox seems to raise skepticism against the use of antioxidants, it may offer new guidelines in antioxidant administration. Specifically, antioxidants may become more effective and less harmful when administered at the appropriate time points and at the appropriate concentrations. This fact could be helpful for athletes who need to enhance their performance or for patients suffering from reactive species-related diseases as an alternative way to improve their health.

\section{Exercise, a commonly used oxidant stimulus}

In the previous sections, the roles of reactive species in several physiological processes were analyzed and the detrimental effects of reactive species and oxidative stress on macromolecules were described. This section will focus on exercise, a very important and commonly examined stimulus of oxidative stress. Exercise is a modality usually adopted as a physiological model for examining the effects of reactive species in human or animal physiology. It demonstrates that reactive species do not always have adverse effects, but they are necessary in physiological processes that are beneficial for human health. A characteristic example of this fact is that the benefits of regular exercise on health are accompanied by repeated episodes of oxidative stress (Fisher-Wellman and Bloomer 2009).

Exercise has been previously shown to affect the blood's redox status and to induce biochemical changes (Nikolaidis and Jamurtas 2009) such as an increase in blood pressure (Nybo et al. 2002), an increase in lactate concentration (Stringer et al. 1994), a decrease in blood pH (Hermansen and Osnes 1972), and a decrease in oxygen partial pressure (Stringer et al. 1994). Specifically, it has been shown that when blood pressure increases, the generation of reactive species in the splachnic circulation of rats increases as well (Hall et al. 1994). Furthermore, lactate seems to be a free radical scavenger and prevents lipid peroxidation by neutralizing $\mathrm{OH}^{-}$and $\mathrm{O}_{2}^{-}$, but not lipid radicals in vitro (Groussard et al. 2000). It has also been proposed that reactive species production in the rat brain mitochondrial respiratory chain is increased in a $\mathrm{pH}$-dependent manner (Selivanov et al. 2008). 
A very important source of reactive species during exercise is the electron transport chain reactions in the mitochondria. It has been established that oxygen uptake is increased about 20 -fold whereas oxygen levels in muscle fibers are increased up to 100-fold (Ji 1999). Thus, the number of electrons leaking during exercise is much higher compared with those leaking at rest.

Xanthine oxidase is one of the major contributors of reactive species during exercise. Xanthine oxidoreductase is an enzyme catalyzing the oxidation of hypoxanthine to xanthine to uric acid in the pathway of purine degradation and exists in two forms. At rest, xanthine oxidoreductase exists as xanthine dehydrogenase, which uses NAD as electron acceptor and does not generate reactive species. However, during exercise, xanthine oxidoreductase is converted to xanthine oxidase, which uses molecular oxygen as the electron acceptor, thereby resulting in $\mathrm{O}_{2}{ }^{-}$ and $\mathrm{H}_{2} \mathrm{O}_{2}$ production (McCord and Fridovich 1968). Xanthine oxidase also generates reactive species through ischemia-reperfusion, which is usually induced by anaerobic exercise or aerobic exercise of high intensity. During ischemia, oxygen uptake in tissues is reduced and ATP is converted to AMP. Xanthine oxidase is produced by the ischemia-triggered proteolytic conversion of xanthine dehydrogenase, oxidizing AMP to hypoxanthine (Nishino et al. 2008). When blood flows again in tissues (reperfusion), hypoxanthine is oxidized to xanthine to uric acid by xanthine oxidase and reactive species are produced (McBride and Kraemer 1999). The role of xanthine oxidase inhibition during exercise has not yet been elucidated as the outcome is dual. It results not only in the inhibition of reactive species generation but also in the inhibition of the production of uric acid, a very potent antioxidant molecule of plasma. It has been previously demonstrated that xanthine oxidase inhibition by allopurinol leads to an increase in antioxidant defense (Gomez-Cabrera et al. 2005), but it has also been shown that allopurinol induces oxidative stress and reduces exercise performance in rats (Veskoukis et al. 2008).

A very common mechanism of reactive species generation during muscle-damaging exercise (e.g., eccentric) is inflammatory response. Polymorphoneutrophils participate in tissue defense via the excretion of lysozyme, $\mathrm{O}_{2}{ }^{--}$, and other reactive species produced by enzymes present in cellular membranes (NADPH oxidase and lipoxygenase; Leeuwenburgh and Heinecke 2001). Furthermore, hemoglobin is oxidized to methemoglobin, leading to $\mathrm{O}_{2}{ }^{-}$ production (Misra and Fridovich 1972), and myoglobin is oxidized, resulting in the formation of peroxyl radicals (Giulivi and Cadenas 1998).

During the last three decades, there have been numerous studies indicating that exercise of sufficient intensity and duration increases the formation of reactive species and that antioxidant mechanisms cannot scavenge them, thus resulting in oxidative stress. Furthermore, it has been demonstrated that free radical generation is greater when the intensity and duration of exercise increases (Finaud et al. 2006; Bloomer 2008). Therefore, exhaustive exercise (aerobic swimming and treadmill running) has been associated with increased oxidative stress (Veskoukis et al. 2008; Michailidis et al. 2007; Nikolaidis et al. 2006). There are various studies demonstrating that different kinds of exercise such as exhaustive treadmill running, ultra- and half-marathon running, downhill running, exhaustive swimming, mountain cycling, and cycling on ergometer induce oxidative stress in humans (Davies et al. 1982; Lovlin et al. 1987; Alessio 1993; Child et al. 1998; Mastaloudis et al. 2001; Palmer et al. 2003; Aguilo et al. 2005; Goldfarb et al. 2005; Tauler et al. 2006; Bloomer et al. 2007; Powers and Jackson 2008; Powers et al. 2011) and animals (Brady et al. 1979; Jenkins et al. 1993; Venditti and Di Meo 1996; Radak et al. 1995, 2002; You et al. 2005; Gomez-Cabrera et al. 2005; Veskoukis et al. 2008; Saborido et al. 2011). Apart from the commonly used markers of oxidative stress, albumin has also been proposed to be an index of tissue oxidative damage. More specifically, it has been found that strenuous exercise increases the oxidized form of albumin (albumin dimmers) in human serum (Imai et al. 2002) and rat skeletal muscle (Veskoukis et al. 2010) and that the oxidative modification of albumin is intensity-dependent (Lamprecht et al. 2008, 2009). These findings indicate that albumin could possibly serve as a new oxidative stress marker.

The field of exercise biology, apart from human studies, is rich in experiments using animal models. The reasons are obvious, but the extrapolation of the results from animals to humans is not easy. Most of the studies use rats or mice which have similarities in their physiology with human subjects. Such experiments are necessary as they help in investigating the mechanisms of in vivo oxidative stress induction and antioxidant action. However, the translation of these results from animals to humans is a rather complicated task. It is noteworthy that rodents (rats and mice) used for laboratory experiments seem to be more sensitive to the effects of dietary antioxidants than humans. Therefore, it is more likely to enhance antioxidant defense or to reduce oxidative damage after dietary antioxidant administration (Halliwell and Gutteridge 2007; Lehr et al. 1999; Loke et al. 2010). Furthermore, rodent models of human diseases in which reactive species are important for their pathology, namely, atherosclerosis, stroke, and amyotrophic lateral sclerosis, appear to be more responsive to plant antioxidant administration than humans. Thus, although the results of relative experiments in rodent models are promising, it is possible that there is no comparable outcome in humans (Halliwell 2001b, 2011). One of the 
main aims of the philosophy of science is the scientific term "predict" and whether it is realistic that animal models can be used to predict human outcomes (Shanks et al. 2009). The prediction is usually related to the recontextualization of knowledge from animal physiology to human physiology. As has been previously defined, recontextualization is a process that extracts meaning from the original context, here animal redox biology (decontextualization), and introduces it into another context, here human redox biology (Bernstein 1990; Nikolaidis and Jamurtas 2009). This process requires a change of meaning (slight or not, depending on the field), leading to some degree of simplification.

\section{Differential effects of plant antioxidants on redox status: in vitro and in vivo comparison}

In the field of sports medicine, there are numerous studies investigating the effects of antioxidants on blood and the redox status of human subjects or animals when they are administered before aerobic exercise. According to its definition, the term "antioxidant" is usually related to its beneficial effects and preventive role against exerciseinduced oxidative stress. The literature is rich in studies examining the in vivo effects of antioxidants when they are administered either individually (vitamins, lipoic acid, $\mathrm{N}$ acetylcysteine) or as part of extracts derived from various plants such as grapes, legumes, and green tea. Additionally, there is an increasing number of studies investigating the effects of antioxidants on in vitro models. An in vivo system could be characterized as biologically interesting but experimentally inaccessible, whereas the corresponding in vitro system could be defined as an experimentally accessible but biologically less interesting system (Strand 1999)

Generally, in the vast majority of the in vitro studies, extracts derived from different plants possess antioxidant properties monitored by their capacity to scavenge free radicals. Specifically, it has been shown that grape extracts (Fauconneau et al. 1997; Bagchi et al. 2000; Murthy 2002;
Stagos et al. 2005, 2007) and extracts or polyphenolic compounds derived from legumes (Beninger and Hosfield 2003; Manna et al. 2004; Heimler et al. 2005; Spanou et al. 2007, 2008; Halliwell 2008) are strong in vitro antioxidant agents and free radical scavengers, but it has also been shown that several grape extracts inhibit catalase and xanthine oxidase activity in vitro, implying a prooxidant action (Spanou et al. 2011). Nevertheless, the case for in vivo experiments in rodents and humans during exercise is rather different. Numerous studies examined the effects of plant extract supplementation on oxidative stress in blood and other tissues, yet the findings are controversial. Interestingly, some studies have demonstrated the antioxidant effects of plant extracts (Voces et al. 1999, 2004; Kim et al. 2005), whereas some others have demonstrated the prooxidant effects of different plant extracts (Morihara et al. 2006; Skarpanska-Stejnborn et al. 2008, 2009; Halliwell 2008, 2011).

Several studies have reported a consistency between the in vitro and in vivo effects of plant antioxidants after the implication of several oxidative stress stimuli, namely, diabetes (Puiggròs et al. 2009; Cho et al. 2006), exposure in xenobiotics (Hwang et al. 2008; Lee et al. 2005), or exposure in reactive oxygen species (Shi et al. 2006). Nevertheless, other studies have demonstrated that the in vitro activity does not always apply in in vivo models (Cherubini et al. 1999; Lotito 2004). It is noticeable that studies examining such comparison in the context of exercise have not been reported. The lack of consistency in experiments comparing the in vitro and in vivo effects of plant extracts on redox status is not surprising. First of all, the assays used to evaluate the in vitro antioxidant activity implicate the scavenging of free radicals that usually are relatively stable, exist only under artificial experimental conditions, and are largely biologically irrelevant (Halliwell and Gutteridge 2007; Scott 1993; Bartosz 2003; Gutteridge and Halliwell 2010). Therefore, it is difficult to translate the in vitro evidence to in vivo outcomes (Gutteridge and Halliwell 2010; Halliwell et al. 2005). Furthermore, the fact that polyphenolic compounds are degraded in metabolites with smaller molecular weight is partly responsible for their

Fig. 1 Simplified figure presenting the recontextualization of knowledge between diet components and food, animals, and humans, in vitro and in vivo experiments

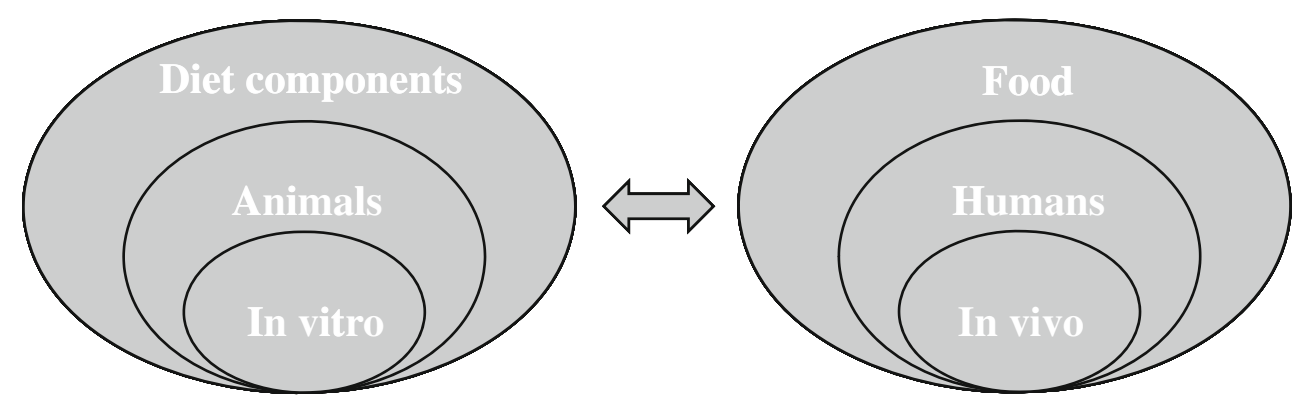

Recontextualized knowledge 
different in vitro and in vivo effects on redox status (Shirai et al. 2006). Besides, polyphenols are metabolized as typical xenobiotics, and such metabolism alters and possibly decreases their antioxidant capacity (Halliwell 2008).

In conclusion, the effects of polyphenols on the redox status in vivo cannot be simply extrapolated from their activities in vitro. The in vitro antioxidant activity of a plant extract seems to differ from its in vivo effect. There is also a common aspect that the contribution of diet antioxidants to protection against oxidative stress or even against diseases (cancer, diabetes, cardiovascular diseases) is a multifactorial case. Specifically, diet antioxidants may be beneficial only in humans whose diet and lifestyle are of poor quality and who are deficient in vital micronutrients and vitamins against overwhelming oxidative damage or the detrimental effects of several diseases related to excessive reactive species production (Hercberg et al. 2007; Halliwell 2009). The process of recontextualization is also applied in the effort of scientists to predict the in vivo effects of plant antioxidants using in vitro models. The recontextualization is based on the need of redox biology to detect the real meaning of experimental evidence applied in vitro. It is a very difficult task which requires much caution in order to obtain real and not overestimated, simplified, or false results.

\section{Concluding remarks}

It is now established that the function of reactive species is highly related to their concentration. The detrimental effects of oxidative stress are linked to the disruption of normal signaling pathways, damage of macromolecules, and disruption of homeostasis. It should be noted that oxygen is not evenly distributed in tissues and cells; therefore, there are sites that are under physiological oxidative stress. It is a difficult task to set a threshold between pathological and physiological oxidative stress. This is in biological accordance with the fact that antioxidants under specific conditions may have a prooxidant action. A commonly used experimental model altering cell or tissue redox status is exercise. This is an example indicating the necessity of reactive species in physiological processes that are beneficial for human health. A characteristic example of this fact is that the benefits of regular exercise on health are accompanied by repeated episodes of oxidative stress. The field of redox biology has been rapidly developed over the last 30 years. The relative literature is rich in studies examining the effects of antioxidants using animal and human models as well as both in vitro and in vivo models. It is obvious that the studies in animal and in vitro models aim to extrapolate their findings to human and in vivo models, respectively. This attempt is usually related to the recontextualization of knowledge, which is presented schematically in Fig. 1. The recontextualization is based on the need of redox biology to detect the real meaning of experimental evidence. This process usually requires a change of meaning (slight or not, depending on the field), leading to some degree of simplification.

Open Access This article is distributed under the terms of the Creative Commons Attribution Noncommercial License which permits any noncommercial use, distribution, and reproduction in any medium, provided the original author(s) and source are credited.

\section{References}

Afzal M, Afzal A, Jones A, Armstrong D (2002) A rapid method for the quantification of GSH and GSSG in biological samples. In: Armstrong D (ed) Methods in molecular biology, vol 186. Oxidative stress biomarkers and antioxidant protocols. Humana, Totowa

Aguilo A, Tauler P, Fuentespina E (2005) Antioxidant response to oxidative stress induced by exhaustive exercise. Physiol Behav 84(1):1-7

Alessio HM (1993) Exercise-induced oxidative stress. Med Sci Sports Exerc 25(2):218-224

Bagchi D, Bagchi M, Stohs SJ, Das DK, Ray SD, Kuszynski CA, Joshi SS, Pruess HG (2000) Free radicals and grape seed proanthocyanidin extract: importance in human health and disease prevention. Toxicology 148:187-197

Bartosz G (2003) Total antioxidant capacity. Adv Clin Chem 37:219 292

Barycki JJ (2007) Antioxidant molecules and redox cofactors: glutathione. In: Banerjee R, Becker DF, Dickman MB, Gladyshev VN, Ragsdale SW (eds) Redox biochemistry. Wiley, Hoboken

Beninger CW, Hosfield GL (2003) Antioxidant activity of extracts, condensed tannin fractions, and pure flavonoids from Phaseolus vulgaris L. seed coat color genotypes. J Agric Food Chem 51 (27):7879-7883

Bernstein B (1990) Structuring of pedagogic discourse: class. Routledge, London

Betters JL, Criswell DS, Shanely RA, Van Gammeren D, Falk D, Deruisseau KC, Deering M, Yimlamai T, Powers SK (2004) Trolox attenuates mechanical ventilation-induced diaphragmatic dysfunction and proteolysis. Am J Respir Crit Care Med 170:1179-1184

Bloomer RJ (2008) Effect of exercise on oxidative stress biomarkers. Adv Clin Chem 46:1-50

Bloomer RJ, Davis PG, Consitt LA, Wideman L (2007) Plasma protein carbonyl response to increasing exercise duration in aerobically trained men and women. Int J Sports Med 28(1):2125

Brady PS, Brady LJ, Ullrey DE (1979) Selenium, vitamin E and the response to swimming stress in the rat. J Nutr 109 (6): 1103-1109

Cherubini A, Beal MF, Frei B (1999) Black tea increases the resistance of human plasma to lipid peroxidation in vitro, but not ex vivo. Free Radic Biol Med 27(3-4):381-387 
Child RB, Wilkinson DM, Fallowfield JL, Donnelly AE (1998) Elevated serum antioxidant capacity and plasma malondialdehyde concentration in response to a simulated half-marathon run. Med Sci Sports Exerc 30(11):1603-1607

Cho EJ, Lee YA, Yoo HH, Yokozawa T (2006) Protective effects of broccoli (Brassica oleracea) against oxidative damage in vitro and in vivo. J Nutr Sci Vitaminol 52(6):437-444

Cotelle N (2001) Role of flavonoids in oxidative stress. Curr Top Med Chem 1:569-590

Cutler RG (1984) In: Johnson JE Jr (ed) Aging and cell function. Plenum Press, New York, pp 1-148

Das KC, Lewis-Molock Y, White CW (1997) Elevation of manganese superoxide dismutase gene expression by thioredoxin. Am J Respir Cell Mol Biol 17:713-726

Davies KJ, Quintanilha AT, Brooks GA, Packer L (1982) Free radicals and tissue damage produced by exercise. Biochem Biophys Res Commun 107:1198-1205

Di Meo S, Venditti P (2001) Mitochondria in exercise-induced oxidative stress. Biol Signals Recept 10:125-140

Fauconneau B, Waffo-Teguo P, Huguet F, Barrier L, Decendit A, Merillon JM (1997) Comparative study of radical scavenger and antioxidant properties of phenolic compounds from Vitis vinifera cell cultures using in vitro tests. Life Sci 61:21032110

Finaud J, Lac G, Filaire E (2006) Oxidative stress: relationship with exercise and training. Sports Med 36(4):327-358

Fisher-Wellman K, Bloomer RJ (2009) Acute exercise and oxidative stress: a 30 year history. Dyn Med 13(8):1

Giulivi C, Cadenas E (1998) Heme protein radicals: formation, fate, and biological consequences. Free Radic Biol Med 24(2):269279

Goldfarb AH, Patrick SW, Bryer S, You T (2005) Vitamin C supplementation affects oxidative stress blood markers in response to a 30 -minute run at $75 \% \mathrm{VO}_{2 \max }$. Int J Sport Nutr Exerc Metab 15(3):279-290

Gomez-Cabrera MC, Borras C, Pallardo FV, Sastre J, Ji LL, Vina J (2005) Decreasing xanthine oxidase-mediated oxidative stress prevents useful cellular adaptations to exercise in rats. J Physiol 567:113-120

Groussard C, Morel I, Chevanne M, Monnier M, Cillard J, Delamarche A (2000) Free radical scavenging and antioxidant effects of lactate ion: an in vitro study. J Appl Physiol 89(1):169-175

Gutteridge JM, Halliwell B (2010) Antioxidants: molecules, medicines, and myths. Biochem Biophys Res Commun 393(4):561-564

Hall DM, Buettner GR, Matthes RD, Gisolfi CV (1994) Hyperthermia stimulates nitric oxide formation: electron paramagnetic resonance detection of NO-heme in blood. J Appl Physiol 77(2):548 553

Halliwell B (1995) Antioxidant characterization. Methodology and mechanism. Biochem Pharmacol 49:1341-1348

Halliwell B (2000) The antioxidant paradox. Lancet 355:1179-1180

Halliwell B (2001a) Free radicals and other reactive species in disease. Encyclopedia of life sciences, pp 1-7

Halliwell B (2001b) Role of free radicals in the neurodegenerative diseases. Therapeutic implications for antioxidant treatment. Drugs \& Aging 18:685-726

Halliwell B (2008) Are polyphenols antioxidants or pro-oxidants? What do we learn from cell culture and in vivo studies? Arch Biochem Biophys 476(2):107-112

Halliwell B (2009) The wanderings of a free radical. Free Radic Biol Med 46:531-542

Halliwell B (2011) Free radicals and antioxidants - quo vadis? Trends Pharmacol Sci 32(3):125-130

Halliwell B, Chirico S (1993) Lipid peroxidation: its mechanism, measurement and significance. Am J Clin Nutr 57(Suppl 1): $715 \mathrm{~S}-725 \mathrm{~S}$
Halliwell B, Gutteridge JMC (1995) The definition and measurement of antioxidants in biological systems. Free Radic Biol Med $18: 125-126$

Halliwell B, Gutteridge JMC (2007) Free radicals in biology and medicine, 4th edn. Clarendon, Oxford

Halliwell B, Rafter J, Jenner A (2005) Health promotion by flavonoids, tocopherols, tocotrienols, and other phenols: direct or indirect effects? Antioxidant or not? Am J Clin Nutr 81:268S276S

Hampton MB, Orrenius S (1998) Redox regulation of apoptotic cell death. Biofactors 18:1-5

Hansford RG, Hogue BA, Mildaziene V (1997) Dependence of $\mathrm{H}_{2} \mathrm{O}_{2}$ formation by rat heart mitochondria on substrate availability and donor age. Bioenerg Biomembr 29:89-95

Heimler D, Vignolini P, Dini MG, Romani A (2005) Rapid tests to assess the antioxidant activity of Phaseolus vulgaris L. dry beans. J Agric Food Chem 53(8):3053-3056

Hercberg S, Ezzedine K, Guinot C, Preziosi P, Galan P, Bertrais S, Estaquio C, Briançon S, Favier A, Latreille J, Malvy D (2007) Antioxidant supplementation increases the risk of skin cancers in women but not in men. J Nutr 137:2098-2105

Hermansen L, Osnes JB (1972) Blood and muscle pH after maximal exercise in man. J Appl Physiol 32(3):304-308

Hertog MGL, Sweetnam PM, Fehily AM, Elwood PC, Kromhout D (1997) Antioxidant flavonols and ischemic heart disease in a Welsh population of men: the Caerphilly Study. Am J Clin Nutr 65:1489-1494

Hooper PL, Hooper PL, Tytell M, Vígh L (2010) Xenohormesis: health benefits from an eon of plant stress response evolution. Cell Stress Chaperones 15(6):761-770

Hwang YP, Choi JH, Han EH, Kim HK, Kang SK, Chung YC, Jeong HG (2008) Protective mechanisms of Aralia continentalis extract against tert-butyl hydroperoxide-induced hepatotoxicity: in vivo and in vitro studies. Food Chem Toxicol 46 (11):3512-3521

Imai H, Hayashi T, Negawa T, Nakamura K, Tomida M, Koda K, Tajima T, Koda Y, Suda K, Era S (2002) Strenuous exerciseinduced change in redox state of human serum albumin during intensive kendo training. Jpn J Physiol 52:35-40

Jenkins RR (1988) Free radical chemistry: relationship to exercise. Sports Med 5:156-170

Jenkins RR, Krause K, Schofield LS (1993) Influence of exercise on clearance of oxidant stress products and loosely bound iron. Med Sci Sports Exerc 25(2):213-217

Ji LL (1999) Antioxidants and oxidative stress in exercise. PSEBM 222:283-292

Ji LL (2007) Antioxidant signaling in skeletal muscle: a brief review. Exp Gerontol 42:582-593

Ji LL, Gomez-Cabrera MC, Vina J (2006) Exercise and hormesis: activation of cellular antioxidant signaling pathway. Ann N Y Acad Sci 1067:425-435

Kang SA, Gang YJ, Park M (1998) In vivo dual effects of vitamin C on paraquat-induced lung damage: dependence on released metals from the damaged tissue. Free Radic Res 28:93-107

Kehrer JP (2007) Reductive stress. In: Fink G (ed) Encyclopaedia of stress. Elsevier, San Diego

Kim SH, Park KS, Chang MJ, Sung JH (2005) Effects of Panax ginseng extract on exercise-induced oxidative stress. J Sports Med Phys Fitness 45(2):178-182

Lamprecht M, Greilberger JF, Schwaberger G, Hofmann P, Oettl K (2008) Single bouts of exercise affect albumin redox state and carbonyl groups on plasma protein of trained men in a workloaddependent manner. J Appl Physiol 104:1611-1617

Lamprecht M, Oettl K, Schwaberger G, Hofmann P, Greilberger JF (2009) Protein modification responds to exercise intensity and antioxidant supplementation. Med Sci Sports Exerc 41:155-163 
Lee HS, Won NH, Kim KH, Lee H, Jun W, Lee KW (2005) Antioxidant effects of aqueous extract of Terminalia chebula in vivo and in vitro. Biol Pharm Bull 28(9):1639-1644

Leeuwenburgh C, Heinecke JW (2001) Oxidative stress and antioxidants in exercise. Curr Medic Chem 8:829-838

Lehr HA, Vajkoczy P, Menger MD, Arfors KE (1999) Do vitamin E supplements in diets for laboratory animals jeopardize findings in animal models of disease? Free Radic Biol Med 26:472-481

Levander OA, Fontela R, Morris VC, Ager AL Jr (1995) Protection against murine cerebral malaria by dietary induced oxidative stress. J Parasitol 81:99-103

Levine RL (2002) Carbonyl modified proteins in cellular regulation, aging, and disease. Free Radic Biol Med 32(9):790-796

Linnane AW, Zhang C, Yarovaya N, Kopsidas G, Kovalenko S, Papakostopoulos P, Eastwood H, Graves S, Richardson M (2002) Human aging and global function of coenzyme Q10. Ann N Y Acad Sci 959:396-411

Loke WM, Proudfoot JM, Hodgson JM, McKinley AJ, Hime N, Magat M, Stocker R, Croft KD (2010) Specific dietary polyphenols attenuate atherosclerosis in apolipoprotein $\mathrm{E}$ knockout mice by alleviating inflammation and endothelial dysfunction. Arterioscler Thromb Vasc Biol 30:749-757

Lotito SB, Frei B (2004) Relevance of apple polyphenols as antioxidants in human plasma: contrasting in vitro and in vivo effects. Free Radic Biol Med 36(2):201-211

Lovlin R, Cottle W, Pyke I (1987) Are indices of radical damage related to exercise intensity? Eur J Appl Physiol 56:313-316

Malm C (2001) Exercise-induced muscle damage and inflammation: fact or fiction. Acta Physiol Scand 171:233-239

Manach C, Scalbert A, Morand C, Remesy C, Jimenez L (2004) Polyphenols: food sources and bioavailability. Am Soc Clin Nutr 79:727-747

Manna C, Migliardi V, Golino P, Scognamiglio A, Galletti P, Chiariello M, Zappia V (2004) Oleuropein prevents oxidative myocardial injury induced by ischemia and reperfusion. J Nutr Biochem 15(8):461-466

Mastaloudis A, Leonard SW, Traber MG (2001) Oxidative stress in athletes during extreme endurance exercise. Free Radic Biol Med 31(7):911-922

Masters C, Pegg M, Cranc D (1986) On the multiplicity of the enzyme catalase in mammalian liver. Mol Cell Biochem 70:113-120

May JM, Qu Z, Whitesell RR, Cobb CE (1996) Ascorbate recycling in human erythrocytes: role of GSH in reducing dehydroascorbate. Free Radic Biol Med 20(4):543-551

McBride JM, Kraemer WJ (1999) Free radicals, exercise, and antioxidants. Nat Strength Cond Assoc 13:175-183

McCord JM, Fridovich I (1968) The reduction of cytochrome c by milk xanthine oxidase. J Biol Chem 243:5753-5760

Michailidis Y, Jamurtas AZ, Nikolaidis MG, Fatouros IG, Koutedakis Y, Papassotiriou I, Kouretas D (2007) Sampling time is crucial for measurement of aerobic exercise-induced oxidative stress. Med Sci Sports Exerc 39:1107-1113

Misra HP, Fridovich I (1972) The generation of superoxide radical during the autoxidation of hemoglobin. J Biol Chem 21:6960 6962

Morihara N, Ushijima M, Kashimoto N, Sumioka I, Nishihama T, Hayama M, Takeda H (2006) Aged garlic extract ameliorates physical fatigue. Biol Pharm Bull 29(5):962-966

Murthy KNC, Singh RP, Jayaprakasha GK (2002) Antioxidant activities of grape (Vitis vinifera) pomace extracts. Toxicology 40:941-947

Mylonas C, Kouretas D (1999) Lipid peroxidation and tissue damage. In Vivo 13:295-309

Nijveldt R, Van Nood E, Van Hoorn ECP, Boelens G, Van Norren K, Van Leeuwen PAM (2001) Flavonoids: a review of probable mechanisms of action and potential applications. Am Soc Clin Nutr 74:48-25

Nikolaidis MG, Jamurtas AZ (2009) Blood as a reactive species generator and redox status regulator during exercise. Arch Biochem Biophys 490:77-84

Nikolaidis MG, Jamurtas AZ, Paschalis V, Kostaropoulos IA, KladiSkandali A, Balamitsi V, Koutedakis Y, Kouretas D (2006) Exercise-induced oxidative stress in G6PD-deficient individuals. Med Sci Sports Exerc 38:1443-1450

Nikolaidis MG, Kyparos A, Hadziioannou M, Panou N, Samaras L, Jamurtas AZ, Kouretas D (2007a) Acute exercise markedly increases blood oxidative stress in boys and girls. Appl Physiol Nutr Metab 32:197-205

Nikolaidis MG, Paschalis V, Giakas G, Fatouros IG, Koutedakis Y, Kouretas D, Jamurtas AZ (2007b) Decreased blood oxidative stress after repeated muscle-damaging exercise. Med Sci Sports Exerc 39:1080-1089

Nishino T, Okamoto K, Eger BT, Pai EF, Nishino T (2008) Mammalian xanthine oxidoreductase-mechanism of transition from xanthine dehydrogenase to xanthine oxidase. FEBS J 275 (13):3278-3289

Nybo L, Møller K, Volianitis S, Nielsen B, Secher NH (2002) Effects of hyperthermia on cerebral blood flow and metabolism during prolonged exercise in humans. J Appl Physiol 93(1):58-64

Palmer FM, Nieman DC, Henson D, McAnulty SR, McAnulty L, Swick NS, Utter AC, Vinci DM, Morrow JD (2003) Influence of vitamin C supplementation on oxidative and salivary Ig A changes following an ultramarathon. Eur J Appl Physiol 89:100-107

Powers SK, Jackson MJ (2008) Exercise-induced oxidative stress: cellular mechanisms and impact on muscle force production. Physiol Rev 88:1243-1276

Powers S, Nelson WB, Hudson MB (2011) Exercise-induced oxidative stress in humans: cause and consequences. Free Radic Biol Med 51:942-950

Puiggròs F, Sala E, Vaqué M, Ardévol A, Blay M, Fernández-Larrea J, Arola L, Bladé C, Pujadas G, Salvadó MJ (2009) In vivo, in vitro, and in silico studies of $\mathrm{Cu} / \mathrm{Zn}$-superoxide dismutase regulation by molecules in grape seed procyanidin extract. J Agric Food Chem 57(9):3934-3942

Radak Z, Asano K, Inoue M, Kizaki T, Oh-Ishi S, Suzuki K, Taniguchi N, Ohno H (1995) Superoxide dismutase derivative reduces oxidative damage in skeletal muscle of rats during exhaustive exercise. J Appl Physiol 79(1):129-135

Radak Z, Kaneko T, Tahara S, Nakamoto H, Ohno H, Sasvari M, Nyakas C, Goto S (1999) The effect of exercise training on oxidative damage of lipids, proteins, and DNA in rat skeletal muscle: evidence for beneficial outcomes. Free Radic Biol Med 27(1-2):69-74

Radak Z, Naito H, Kaneko T, Tahara S, Nakamoto H, Takahashi R, Cardozo-Palaez F, Goto S (2002) Exercise training decreases DNA damage and increases DNA repair and resistance against oxidative stress of proteins in aged rat skeletal muscle. Pflugers Arch 445(2):273-278

Rice-Evans CA, Miller NJ, Paganga G (1996) Structure-antioxidant activity relationships of flavonoids and phenolic acids. Free Radic Biol Med 20:933-956

Rowe PM (1996) $\beta$ carotene takes a collective beating. Lancet 347:249

Saborido A, Naudí A, Portero-Otín M, Pamplona R, Megías A (2011) Stanozolol treatment decreases the mitochondrial ROS generation and oxidative stress induced by acute exercise in rat skeletal muscle. J Appl Physiol 110(3):661-669

Schneider BS, Tiidus PM (2007) Neutrophil infiltration in exerciseinjured skeletal muscle: how do we resolve the controversy? Sports Med 37:837-856 
Scott G (1993) Autoxidation and antioxidants: historical perspectives. In: Scott G (ed) Atmospheric oxidation and antioxidants, vol 1. Elsevier Science, Amsterdam, pp 1-44

Selivanov VA, Zeak JA, Roca J, Cascante M, Trucco M, Votyakova TV (2008) The role of external and matrix $\mathrm{pH}$ in mitochondrial reactive oxygen species generation. J Biol Chem 283(43):2929229300

Sen CK (1998) Redox signalling and the emerging therapeutic potential of thiol antioxidants. Biochem Pharmacol 55:17471758

Shanks N, Greek R, Greek J (2009) Are animal models predictive for humans? Philos Ethics Humanit Med 15(4):2

Shi GF, An LJ, Jiang B, Guan S, Bao YM (2006) Alpinia protocatechuic acid protects against oxidative damage in vitro and reduces oxidative stress in vivo. Neurosci Lett 403(3):206-210

Shirai M, Kawai Y, Yamanishi R, Kinoshita T, Chuman H, Terao J (2006) Effect of a conjugated quercetin metabolite, quercetin 3glucuronide, on lipid hydroperoxide-dependent formation of reactive oxygen species in differentiated PC-12 cells. Free Radic Res 40(10):1047-1053

Sies H (1991) Oxidative stress: oxidants and antioxidants. Academic, New York

Sies H, Jones DP (2007) Oxidative stress. In: Fink G (ed) Encyclopaedia of stress. Elsevier, San Diego

Simic MG (1988) Oxygen radicals in biology and medicine. Plenum, New York

Sjodin B, Hellsten Westing Y, Apple FS (1990) Biochemical mechanisms for oxygen free radical formation during exercise. Sports Med 10:236-254

Skarpanska-Stejnborn A, Pilaczynska-Szczesniak L, Basta P, DeskurSmielcka E, Horoszkiewicz-Hassan M (2008) The influence of supplementation with artichoke (Cynara scolymus L.) extract on selected redox parameters in rowers. Int $\mathrm{J}$ Sport Nutr Exerc Metab 18(3):313-327

Skarpanska-Stejnborn A, Pilaczynska-Szczesniak L, Basta P, DeskurSmielecka E (2009) The influence of supplementation with Rhodiola rosea L. extract on selected redox parameters in professional rowers. Int J Sport Nutr Exerc Metab 19(2):186-199

Spanou C, Stagos D, Tousias L, Angelis A, Aligiannis N, Skaltsounis AL, Kouretas D (2007) Assessment of antioxidant activity of extracts from unique Greek varieties of Leguminosae plants using in vitro assays. Anticancer Res 27(5):3403-3410

Spanou C, Bourou G, Dervishi A, Aligiannis N, Angelis A, Komiotis D, Skaltsounis AL, Kouretas D (2008) Antioxidant and chemopreventive properties of polyphenolic compounds derived from Greek legume plant extracts. J Agric Food Chem 56(16):6967-6976

Spanou C, Veskoukis AS, Stagos D, Liadaki K, Anastasiadi M, Haroutounian SA, Tsouka M, Tzanakouli E, Kouretas D (2011) Effects of grape extracts on the in vitro activity of enzymes involved in oxidative stress regulation. Vivo 25(4):657-662

Stagos D, Kazantzoglou G, Magiatis P, Mitaku S, Anagnostopoulos K, Kouretas D (2005) Effects of plant phenolics and grape extracts from Greek varieties of Vitis vinifera on mitomycin $\mathrm{C}$ and topoisomerase I-induced nicking of DNA. Int $\mathrm{J}$ Mol Med 15:1013-1022

Stagos D, Spanou C, Margariti M, Stathopoulos C, Mamuris Z, Kazantzoglou G, Magiatis P, Kouretas D (2007) Cytogenetic effects of grape extracts (Vitis vinifera) and polyphenols on mitomycin C-induced SCEs in human blood lymphocytes. J Agric Food Chem 55:5246-5252

St-Pierre J, Buckingham JA, Roebuck SJ, Brand MD (2002) Topology of superoxide production from different sites in the mitochondrial electron transport chain. J Biol Chem 277:44784-44790

Strand R (1999) Towards a useful philosophy of biochemistry: sketches and examples. Foundations of Chemistry 1:271-294

Stringer W, Wasserman K, Casaburi R, Pórszász J, Maehara K, French W (1994) Lactic acidosis as a facilitator of oxyhemoglobin dissociation during exercise. J Appl Physiol 76 (4): 1462-1467

Suh JK, Poulsen LL, Ziegler DM, Robertus JD (1999) Yeast flavincontaining monooxygenase generates oxidizing equivalents that control protein folding in the endoplasmic reticulum. Proc Natl Acad Sci USA 96:2687-2691

Tauler P, Sureda A, Cases N, Aguilo A, Rodriguez-Marroyo JA, Villa G, Tur JA, Pons A (2006) Increased lymphocyte antioxidant defences in response to exhaustive exercise do not prevent oxidative damage. J Nutr Biochem 17(10):665-671

Venditti P, Di Meo S (1996) Antioxidants, tissue damage, and endurance in trained and untrained young male rats. Arch Biochem Biophys 331(1):63-68

Veskoukis AS, Nikolaidis MG, Kyparos A, Kokkinos D, Nepka C, Barbanis S, Kouretas D (2008) Effects of xanthine oxidase inhibition on oxidative stress and swimming performance in rats. Appl Physiol Nutr Metab 33:1140-1154

Veskoukis AS, Kyparos A, Stagos D, Kouretas D (2010) Differential effects of xanthine oxidase inhibition and exercise on albumin concentration in rat tissues. Appl Physiol Nutr Metab 35(3):244 250

Voces J, Alvarez AI, Vila L, Ferrando A, Cabral de Oliveira C, Prieto JG (1999) Effects of administration of the standardized Panax ginseng extract G115 on hepatic antioxidant function after exhaustive exercise. Comp Biochem Physiol C Pharmacol Toxicol Endocrinol 123(2):175-184

Voces J, Cabral de Oliveira AC, Prieto JG, Vila L, Perez AC, Duarte ID, Alvarez AI (2004) Ginseng administration protects skeletal muscle from oxidative stress induced by acute exercise in rats. Braz J Med Biol Res 37(12):1863-1871

Wendel A (1987) Measurement of in vivo lipid peroxidation and toxicological significance. Free Radic Biol Med 3(5):355358

You T, Goldfarb AH, Bloomer RJ, Nguyen L, Sha X, McKenzie MJ (2005) Oxidative stress response in normal and antioxidant supplemented rats to a downhill run: changes in blood and skeletal muscles. Can J Appl Physiol 30(6):677-689

Young IS, McEneny J (2001) Lipoprotein oxidation and atherosclerosis. Biochem Soc Trans 29(2):358-362 